\title{
“No Central Stage”: Telegram-based activity during the 2019 protests in Hong Kong
}

\author{
Authors: Aleksandra Urman ${ }^{\text {ab* }}$, Justin Chun-ting $\mathrm{Ho}^{c d}$ and Stefan Katz ${ }^{\mathrm{e}}$ \\ ${ }^{a}$ Institute of Communication and Media Studies, University of Bern, Bern, Switzerland; ${ }^{b}$ Social Computing Group, \\ Department of Informatics, University of Zurich, Zurich, Switzerland; 'School of Social and Political Science, \\ University of Edinburgh, Edinburgh, UK; ${ }^{d}$ Centre for European Studies and Comparative Politics, Sciences Po, \\ Paris, France; ${ }^{e}$ polyflow LLC, Switzerland. \\ Corresponding author’s email: urman@ifi.uzh.ch
}




\title{
"No Central Stage": Telegram-based activity during the 2019 protests in Hong Kong
}

\begin{abstract}
We examine Telegram-based activities related to the 2019 protests in Hong Kong thus presenting the first study of a large Telegram-aided protest movement. We contribute to both - scholarship on Hong Kongese protests and research on social media-based protest mobilization. For that, we rely on the data collected through Telegram's API and a combination of network analysis and computational text analysis. We find that the Telegram-based network was cohesive ensuring efficient spread of protest-related information. Content spread through Telegram predominantly concerned discussions of future actions and protestrelated on-site information (i.e., police presence in certain areas). We find that the Telegram network was dominated by different actors each month of the observation suggesting the absence of one single leader. Further, traditional protest leaders - those prominent during the 2014 Umbrella Movement, - such as media and civic organisations were less prominent in the network than local communities. Finally, we observe a cooldown in the level of Telegram activity after the enactment of the harsh National Security Law in July 2020. Further investigation is necessary to assess the persistence of this effect in a long-term perspective.
\end{abstract}

Word count (incl. references, excl. Figure captions and Tables): 7994.

\section{Introduction}

In 2019, Hong Kong has experienced massive Anti-Extradition Law Amendment Bill (Anti-ELAB) protests. They were first triggered in the end of March 2019 by a proposed bill that would have allowed Hong Kong to send fugitives to jurisdictions without existing bilateral extradition agreements with Hong Kong, including Mainland China, Taiwan and Macau. The proposed bill was said to be prompted by a murder case in Taiwan in 2018. Still, the fact that the proposed legislation, once passed, would allow extradition to China has raised considerable doubts about the government's motivations. Despite the widespread public concerns, the bill was set to pass the second reading in the Hong Kong's Legislative Council (LegCo) on June 12. In response, tens of thousands of protesters surrounded the LegCo and forced the cancellation of the meeting. Although the government announced the suspension of the bill on June 15, the protest evolved to incorporate other demands including the complete withdrawal of the bill and the retraction of the riot characterization of the June 12 protest (Lee et al., 2019). The protests were marked by police brutality, indiscriminate attack on citizens by pro-government thugs, and the government's refusal to back down, and eventually turned into a series of recurring weekly protests until early 2020 when the COVID-19 pandemic brought a recess (Lee et al., 2019). The political climate has become even more unfavourable to the protests after China imposed a harsh Security Law on Hong Kong 
on June 30, 2020, under which secession and subversion activities are punishable with up to life imprisonment.

The Anti-ELAB protests have often been described as leaderless and decentralized (Kent, 2019; Rachman et al., 2019; Vincent, 2019). In Hong Kong, there has been widespread antipathy among protesters towards a centralized movement leadership since the later stage of Umbrella Movement in 2014. As a result, the idea of “no central stage” (無大台) has been central to the 2019 Anti-ELAB protests since its early stage (Lee et al., 2019). In the absence of a leading organisation, protesters coordinated their activities through encrypted messaging apps, most notably Telegram, as well as online discussion forums (Ku, 2020; Lee et al., 2019; Lee, 2020). These platforms allowed a high volume of information flow and strategic discussions to take place with the participants remaining anonymous (Lee et al., 2019). While previous research has analyzed Anti-ELAB protest mobilization on online discussion forums (Lee, 2020), Telegram remains an uncharted territory despite its importance in the protests both in Hong Kong in 2019 and beyond - i.e., in Belarus in 2020 or in Russia in 2019.

In this paper, we examine Telegram-based activities related to the Hong Kong's protests of 2019 - one of the largest Telegram-aided protest movements to date - using a combination of network analysis and computational text analysis techniques. With this study, we aim to contribute to both, the scholarship on Hong Kong's movement in particular, and on social media ${ }^{1}$-aided protest mobilization in general.

\section{Social media and protest mobilization in authoritarian regimes and beyond}

Internet penetration rates and the spread of social media are positively correlated with protest potential, especially in authoritarian states (Howard et al., 2011). Researchers have identified mechanisms through which the Internet and social media can increase protest mobilization potential. Jost and colleagues (2018) outline the following mechanisms: (1) social media facilitates the citizens' access to information that is relevant to protest coordination such as information about police presence, violence, arrests or possible medical and legal help; (2) social media help in spreading motivational and emotional messages regarding the protest. This is echoed by Ruijgrok (2017) who argues that in authoritarian regimes the internet contributes to protest actions through the following: (1) lowering coordination risks; (2) providing citizens with access to alternative information, thus affecting their attitudes; (3) removing information uncertainty for potential protestors; (4) facilitating the spread of graphic depictions of the protest in images and videos, which can be especially powerful for mobilization. Bennett and Segerberg (2012) have come up with the concept of "connective action” arguing that social media platforms have changed the logic of protest mobilization. According to the authors, pre-social media protest movements were functioning through collective action that required the formation of organizational structures and collective identities. In contrast, social media era protest movements are based on connective action at the heart of which lies personalized content sharing through social networks.

1 We regard Telegram as a social media platform since it allows users to create and publicly share content with others as well as connect with other users and create online communities. 
The event that triggered the increase in scholarly attention to social media platforms in the context of protest mobilization was the Arab Spring as social media platforms, specifically Facebook and Twitter, played a crucial instrumental role during the protests (Comunello \& Anzera, 2012; Howard et al., 2011). Since then, numerous studies have examined the role of social media in protest mobilization in different contexts such as the Indignados and Occupy movements (González-Bailón \& Wang, 2016); the Euromaidan in Ukraine (Lyebyedyev \& Makhortykh, 2018); protests in Venezuela (Morales et al., 2012), in Russia (Spaiser et al., 2017) and in Turkey (Tufekci \& Wilson, 2012); the so-called Umbrella Movement of 2014 in Hong Kong (Lee et al., 2015). These and other studies have demonstrated that a particular effect of social media on protest mobilization is not universal and depends on the local context and offline actions (González-Bailón \& Wang, 2016; Jost et al., 2018). Hence, further empirical studies on social media-aided mobilization are necessary to understand the phenomenon better. In addition, the effects are not universal across all social media platforms, with some of them being more suitable and efficient for protest organization than others, depending on the combination of the local context and platform affordances (Comunello et al., 2016).

Large authoritarian countries such as China and Russia are known for their successes in limiting free speech and manipulating public discourses online. They practice so-called "network authoritarianism" leveraging "ICTs [information and communication technologies] and media regulation to carefully control the expression of dissent in a way that gives the impression of limited freedom of expression without allowing dissent to gain traction” (Maréchal, 2017, P. 36). Such regimes engage in censorship by disinformation and compete with online dissenters by trying to undermine their credibility (Maréchal, 2017; Tufekci, 2017).

Evolution of the measures that autocratic regimes employ to curb online protest mobilization inevitably triggers the evolution of the protesters' tactics. This includes switching to new platforms. If Facebook and Twitter were the most popular platforms during the Arab Spring and a few years later, in recent years, their place was taken by Telegram - a free cloud-based messaging platform. Media reports highlight that in 2019-2020 Telegram has been one of the key platforms for protest coordination and mobilization in Russia (Ebel, 2019); Belarus (Dans, 2020); Catalonia (Clarke, 2019) and Hong Kong (Banjo, 2019). In the next section, we describe Telegram and its functionality and outline what, in our opinion, makes it attractive for protesters.

\section{Telegram’s “digital resistance”}

Telegram is a privacy-focused app that was founded in 2013 by Pavel and Nikolai Durov - two entrepreneurs of Russian origins - after they fled Russia due to legal trouble with the Russian state over freedom of speech. Telegram's FAQ highlights its privacy and anti-censorship focus: "if criticizing the government is illegal in some country, Telegram won't be a part of such politically motivated censorship. This goes against our founders' principles. While we do block terrorist (e.g. ISIS-related) bots and channels, we will not block anybody who peacefully expresses alternative opinions” (“Telegram F.A.Q.," n.d.).

In 2018 Russia attempted - unsuccessfully - to block Telegram. This happened after Durov refused to give Russian authorities access to user data. In response, he called for "digital resistance” - an initiative that, 
according to Telegram's spokesman, is “a community of anonymous developers who created proxy servers around the world to help Telegram remain accessible for Russian users” (Liao \& Lomas, 2020). Moreover, Durov and Telegram openly support protests in authoritarian states other than the CEO's home country such as, most recently, the protests in Belarus (Partz, 2020). And in 2019, when Hong Kongese Telegram users complained that one of Telegram's features allowed the identification of their phone numbers, thus potentially enabling local law enforcement to find out political activists' identities, Telegram swiftly rolled out an update to close this security loophole (Schectman, 2019). Durov's commitment to users' privacy, Telegram's sturdiness in the face of the attempts to block it in Russia and Durov's support for the protests have undoubtedly increased the app's credibility in the eyes of the protesters in Russia and, possibly, beyond.

From a technical point of view, crucially for political activists in authoritarian regimes, Telegram combines "enhanced privacy and anonymity along with the opportunities to gain publicity (through channels) and coordinate and mobilize (through groups)" (Urman \& Katz, 2020). Most of the app's features - i.e., public and private channels, public and private groups, encryption, secret chats, unsend anything and anonymous forwarding - have been outlined by Urman and Katz (2020) in detail, along with the reasons why these features are helpful to users who want to gain publicity while preserving anonymity.

In addition to the functions mentioned, other features of Telegram that are of high importance in the context of protests are the absence of algorithmic filtering, advertisements and the difficulty of searching for new channels on Telegram. Due to the absence of algorithmic filtering, the users are in control of what they see on the app. Since channels and groups are difficult to search for, their growth and popularity depend on them being referenced by other - already popular - Telegram sources. This, along with the absence of paid-for content promotion, means that it is more difficult for authoritarian states to spam and hijack conversations on Telegram compared to other platforms such as Facebook or Twitter. Finally, as the example of Russia - and, more recently, Belarus - shows, Telegram is difficult to block - a feature highly relevant for protesters who fight against repression by authoritarian governments.

Despite Telegram's popularity with protesters around the world, scholars have not examined the platform in this context yet. We find this to be a significant research gap. The platform's affordances are very different from those of Facebook or Twitter and thus Telegram-based protest mobilization might function very differently from the one that took place on the other platforms. For instance, personalized public sharing - the foundation of so-called "connective action" (Bennett \& Segerberg, 2012) - does not play as much role on Telegram due to the way the platform is organized. One sees either personal messages from their friends or posts from public channels one has subscribed to in their feed, not what their friends have publicly reposted - the latter feature is absent on Telegram. In this paper, we scrutinize the way protest mobilization takes place on the platform using the Hong Kong protests of 2019 - one of the largest Telegram-aided pro-democratic movements - as a case study.

\section{Research questions}

The main goal of the present study is an explorative analysis of the Telegram-based activity related to the 2019 protests in Hong Kong. Telegram was used by the protesters to coordinate their activities (Ting, 2020) but the dynamics of the use of Telegram during the protests is unclear. For instance, at what point Telegram, previously not very popular in Hong Kong, became the "app to go" for the protesters, and how fast the movement grew on the platform. The first research question we ask is: 
RQ1: What were the dynamics of Hong Kong protest movement's development on Telegram?

One of the most important mechanisms through which social media can positively affect protest mobilization is the facilitation of the spread of protest-related information, motivational and coordinational messages (Jost et al., 2018; Ruijgrok, 2017). However, the efficient spread of information is crucial for this mechanism to have influence. In the context of social media, potential efficiency of information spread can be assessed with the help of network theory (González-Bailón \& Wang, 2016). In practice, online networks are often sparse and fragmented. Such structures hamper the diffusion of information in a network, thus decreasing the potential of social media-based mobilization (GonzálezBailón \& Wang, 2016). For it to be maximized, there should be actors that act as structural bridges who facilitate information diffusion across different communities in the network. Ideally, such information diffusion across communities would lead to increased cohesiveness - that is, less fragmentation, - of the network making information spread more effective.

The basis of wide information diffusion on Telegram is formed by public channels and groups that are not easily searchable and whose discoverability depends on them being cited by other channels. Hence, the analysis of the coherence of Telegram's citation network is particularly important for the assessment of the efficiency of information diffusion on the platform. That is what we address with the second research question:

RQ2: How fragmented was the citation network of public Telegram channels and groups related to the Hong Kong protest movement of 2019?

Not only the efficiency of information diffusion is essential but also the content that is being spread. Information related to police presence, availability of medical and legal help, and coordination-related messages is especially relevant (Jost et al., 2018). In addition, emotional messages regarding the protest are helpful for mobilization (Jost et al., 2018). As content is crucial for effective mobilization, we address the following research question:

RQ3: Which topics were discussed by political activists on Telegram in relation to the Hong Kong's protests of 2019?

Scholars have claimed that social media create opportunities for the development of "leaderless" protest movements (Bennett \& Segerberg, 2012; Castells, 2015). Yet, empirical research on social media-enabled protests of the early 2010s shows that leaders remain important for such movements both online, and offline (Gerbaudo, 2012; Poell et al., 2016) even if contemporary protesters prefer portraying the movements as "leaderless” (Poell et al., 2016).

On Telegram, in the absence of a public feed sharing function, the major means for coordination and communication are public channels and groups. Groups are essentially group chats where anyone can post, while channels are normally administered by few people, and only these people - channel administrators - can post to a given channel. This structure is strikingly different from that of Facebook and Twitter and, at the first glance, is perhaps more conducive to the emergence of leaders (i.e., specific channels coordinating protest actions) rather than to the development of a completely leaderless protest as 
the 2019 protests in Hong Kong (Ting, 2020). To scrutinize this claim we pose the following research question:

RQ4: What are the dynamics of leadership in Telegram-based activities during the 2019 Hong Kong protests?

Telegram has proven to be somewhat immune to the Internet-based measures set to curb its influence, as unsuccessful attempts to block it in Russia and Belarus show. However, online censorship is not the only possible way of curbing Internet-based protest mobilization. On June 30, 2020, China imposed a harsh Security Law on Hong Kong, under which secession and subversion activities are now punishable with up to life imprisonment (Hong Kong Government, 2020). The law has created a chilling effect across Hong Kong: pro-democracy groups, including Demosisto founded by one of the most famous pro-democracy activists Joshua Wong, were disbanded; several prominent pro-democracy activists, including Nathan Law, fled Hong Kong; Hong Kong people took down their Twitter and Facebook accounts; shops removed "Lennon Walls" - walls made up of Post-it Notes bearing pro-democracy messages to show support of the protests; and journalists have erased their names from digital archives (Agence FrancePresse, 2020; Barron, 2020; Leigh et al., 2020; Liu \& Yang, 2020). Hong Kong Telegram users, particularly channel administrators, have become the targets of multiple arrests in the past (Mozur \& Stevenson, 2019; Siu \& Leung, 2020; Wong, 2020), which has prompted the app to push changes to protect the identity of Hong Kong protesters (Schectman, 2019). Against this background, even though Telegram was not targeted specifically by the Security Law, it is possible that the enactment of the Law has affected Telegram-based activities as well. If that is the case, the example of Hong Kong would set a troubling precedent in the context of social media-enabled mobilization in autocratic regimes, suggesting that even privacy-focused platforms that successfully resist online censorship might not be an effective tool in a fight against a powerful authoritarian regime. In connection to this, we examine the final research question of the present study:

RQ5: Did the enactment of the Security Law affect the activities of Hong Kong's political Telegramsphere?

In the following sections, we describe the data and methodology used in the analysis, present the results and discuss their implications.

\section{Data and Methods}

\section{Data collection}

We collected the data from 1806 public Telegram channels from the Hong Kong Telegram ecosystem. The data was collected using Telegram’s open API and Telethon Python library (Exo 2020) using Exponential Discriminative Snowball sampling (Goodman 1961; Biernacki and Waldorf 1981; Baltar and Brunet 2012). We employed the data collection methodology previously used in a study on far-right Telegram channels (Urman \& Katz, 2020). 
Unlike in traditional sampling, the initial seed was not sampled randomly but chosen by us - a method appropriate to reach hidden populations with specific properties (Etikan 2016). As the initial seed we chose the channel @dadfindboy, which at the time of the protests was one of the most prominent channels among Hong Kong activists according to tgstat.com. Using snowballing (see Urman \& Katz (2020) for the detailed outline of the method), we collected full histories of 1806 public channels and groups. Based on these histories, we then constructed a directed citation network of Telegram sources. In this network, a node corresponds to a Telegram channel or chat. An edge between two nodes corresponds to a mention/repost with the weight being equal to the number of mentions/reposts (i.e., if channel A mentions channel B 3 times during the observation period, there is a directed edge from A to B with weight 3). In total, the resulting full network includes 1806 nodes with full histories (“source nodes”), 58563 nodes mentioned by them for which full histories were not collected, and 353386 weighted edges.

\section{Methods}

To answer RQ1 and assess how the observed citation network developed, we first examined the rates of its growth. As proxies to measure this, we used the number of edges, the total number of source nodes and the number of newly added source nodes in the network observed per month. New source nodes here correspond to the channels that became active within a specific month. For this analysis, we used the observation period starting in January 2019 - three months ahead of the introduction of the Extradition Bill that triggered the start of the protests in Hong Kong in the end of March 2019.

To address RQ2, we looked at the level of network fragmentation in different months. For this, we computed modularity scores using Louvain algorithm (Blondel et al., 2008) for the snapshots of the network, each snapshot corresponding to one month of the observation.

To answer RQ3 and evaluate the content that was shared on Telegram and discussed by the protesters, we employed quantitative text analysis techniques. Due to the high number of messages posted on Telegram, it would have been difficult in terms of the necessary computational resources to run analysis on the full sample. For this reason, we decided to restrict the analysis to the most important channels in the observed citation network. For that, we have applied the HITS algorithm (Kleinberg, 1998) to the network and identified the twenty nodes (channels) with the highest Hub and Authority scores. Channels with high authority scores serve as important sources of the primary content and are often cited by the others; those with high hub scores, on the other hand, function more like directories of useful information from other sources (Kleinberg, 1998). Hubs heavily link to authorities, but are not necessarily often linked to; authorities are frequently cited by hubs, but do not necessarily cite other channels. By including both types in our analysis, we were able to encompass both types of sources - authorities who might have acted as coordinators or main sources of new information and hubs that might have served as aggregators of information from different sources. We believe both types are important in the context of protest mobilization.

A total of 3,558,662 messages were extracted. To proceed with the analysis, we first used Jieba Chinese text segmentation tool (Sun, n.d.) with a supplementary Cantonese dictionary (Ho, 2020) to split the Telegram contents into Cantonese word tokens. We then used the tokens to train a continuous bag-ofwords (CBOW) model using Word2vec. CBOW is a neural network-based algorithm to learn the underlying vector representations of words in the high-dimensional vector space (Mikolov et al., 2013). In the model, each word is represented by a 100-dimensional vector where words that have similar meaning 
will have similar representations in the vector space. Document embeddings were then calculated by averaging all the words within each message. To examine the topics within the corpus and their prevalence, we used an unsupervised k-means clustering method to cluster the document embeddings (Sculley, 2010). The optimal number of $\mathrm{k}$ was determined through the within-cluster sum of squares elbow method for 1 to 50 clusters (Figure 1). Following this, we used a k-means method with $\mathrm{k}=12$, where each cluster represents a topic within the contents. We then validate the clustering by manually reading random samples of messages from each cluster until saturation is reached.

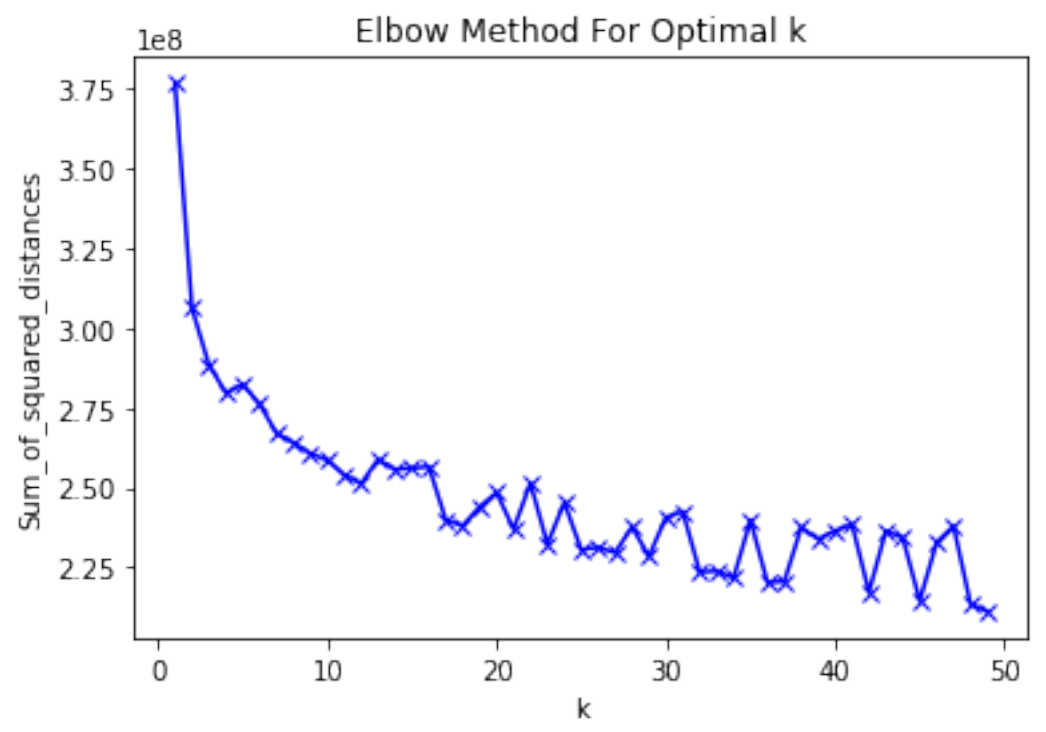

Figure 1. Elbow Method for Optimal k.

To answer RQ4 and check whether there is evidence of the presence of specific leaders, we have repeated the HITS-based analysis for 8 monthly snapshots (from May 2019 to December 2019), in each case taking into account only the messages posted within a specific month, and constructing a monthly snapshot of a citation network. For each monthly network, we extracted top-10 channels by Authority and Hub scores, and then checked their position in terms of Authority and Hub scores in other months. We suggest that the dominance of a single or few nodes throughout the duration of the protests would indicate that those nodes acted as de-facto leaders of the protest. The absence of such dominance would indicate that there were no specific leaders, with different groups taking over at different times and suggesting that the protest was in fact leaderless - at least in the traditional sense of leadership characteristic for collective movements of the past.

To check whether the National Security Law introduced in July 2020 has significantly affected the activities within the observed Telegram network and thus answer RQ5, we employed Interrupted Time Series Analysis (McDowall et al., 2019) applied to the daily rates of edge formation in the observed network. We examined the period from March 2020 to the end of September 2020. The cut-off point for the start of the observation was chosen to isolate the effects of other major events such as the beginning of the COVID-19 pandemic or the protests in Hong Kong in 2019 on the timeseries. In total, the data comprised 214 points (122 - pre-law; 92 - after-law), each corresponding to one day. No autocorrelation 
was observed. We used a bootstrap model with 1000 replications of the main model with randomly drawn samples with alpha=0.05. We used "its.analysis” package in R (English, 2019) for this analysis.

\section{Results}

\section{Dynamics of the network development}

The rapid growth of the network started in June 2019, as reflected by the spike in the number of new Telegram channels (Figure 2; red lines correspond to: the announcement of the Anti-Extradition Bill in the end of March 2019, and the enactment of the National Security law in July 2020). The growth rate in terms of the number of new channels peaked in November 2019, the most heated period of the protests in Hong Kong. Since then, the growth rate has decreased, however new channels are still being added every month, though in lower numbers than in summer and fall of 2019 (Figure 2).

The number of edges in the network (Figure 2) follows a slightly different pattern. The amount of connections in the form of mentions or reposts between Telegram channels started surging in July 2019, thus slightly lagging behind the spike in the number of new channels. It peaked around January 2020 two months after the peak in the number of new channels. Overall, the pattern of edge formation closely resembles that of new channel formation with the spikes in the latter preceding those in the former by 1-2 months.

\section{Network fragmentation}

We have computed modularity scores for each month between January 2019 and September 2020 to assess the level of network fragmentation in each month. The distribution of the scores is depicted in Figure 2. In the beginning of 2019, the network was highly fragmented with the modularity scores for each month from January 2019 to June 2019 being above 0.6. In practice, modularity score values above 0.5 are a significant departure from what could be observed in a random network, thus indicating the presence of a strong community structure, and, consequently, of structural holes (González-Bailón \& Wang, 2016; Newman \& Girvan, 2004). In July 2019, the modularity score fell to below 0.5, suggesting that the network became more cohesive between June and July 2019. 

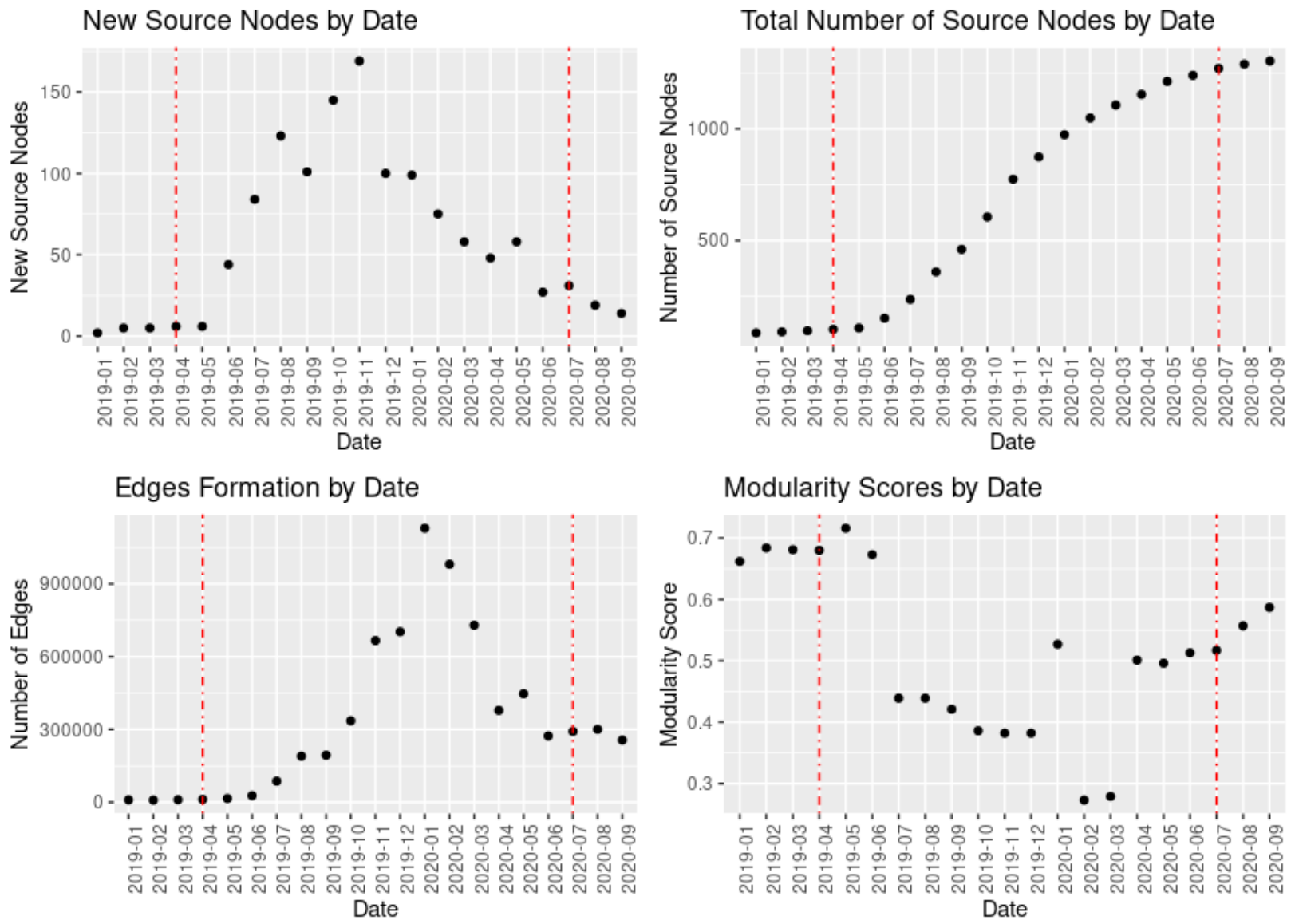

Figure 2. Dynamics of network development. Red lines denote the announcement of the Anti-Extradition Bill in the end of March 2019 and the introduction of the National Security Law in July 2020.

Our observation about the drastic decrease in the level of network fragmentation between June and July 2019 prompted us to check which channels have contributed to the increased coherence by connecting the most active political community to the others in the network. For this, we calculated brokerage scores for all the nodes (channels) in this most active community in June 2019. The most active political community was inferred from the network structure - i.e., we have qualitatively examined the biggest (by the number of nodes) communities in the network, and qualitatively checked the nodes with the highest authority and hub scores in each of them. The biggest community by the share of nodes (comprising $20.21 \%$ of all nodes in the June 2019 network) was identified as highly politically active, with some of its key nodes turning into major actors - by hub or authority scores - in the overall network at later stages. For each node in this community, we calculated brokerage scores corresponding to one of the following roles (Gould \& Fernandez, 1989):

- Gatekeeper role - brokers who serve as bridges between their own community and the others through incoming contact.

- Representative role - bridges between their own community and the others through outgoing contact.

- Liaison role - bridges between nodes from two groups they do not belong to.

- Coordinator role - facilitate contact between two nodes in their own group. 
The first three roles described can be referred to as global brokers as they facilitate connections on the overall network level. The last role refers to local brokerage - coordinators facilitate connections between nodes in their own community.

We have then calculated the association between the brokerage scores and authority and hub scores. We find that there is no association between global brokerage and authority or hub scores. That is, channels that helped mediate contact between the political community in June 2019, at the start of the political organization on Telegram, were not important in terms of citation network (see Figure 3 for the illustration of association between authority scores and brokerage scores). However, there is weak association between local brokerage scores and authority meaning that highly authoritative channels in the network were important for establishing contact between other channels in the politically active community. Still, the absence of association between global brokerage and hub/authority scores suggests that in June 2019, at the beginning of the network evolution, the connection of the political community to the others was facilitated predominantly by less prominent channels.
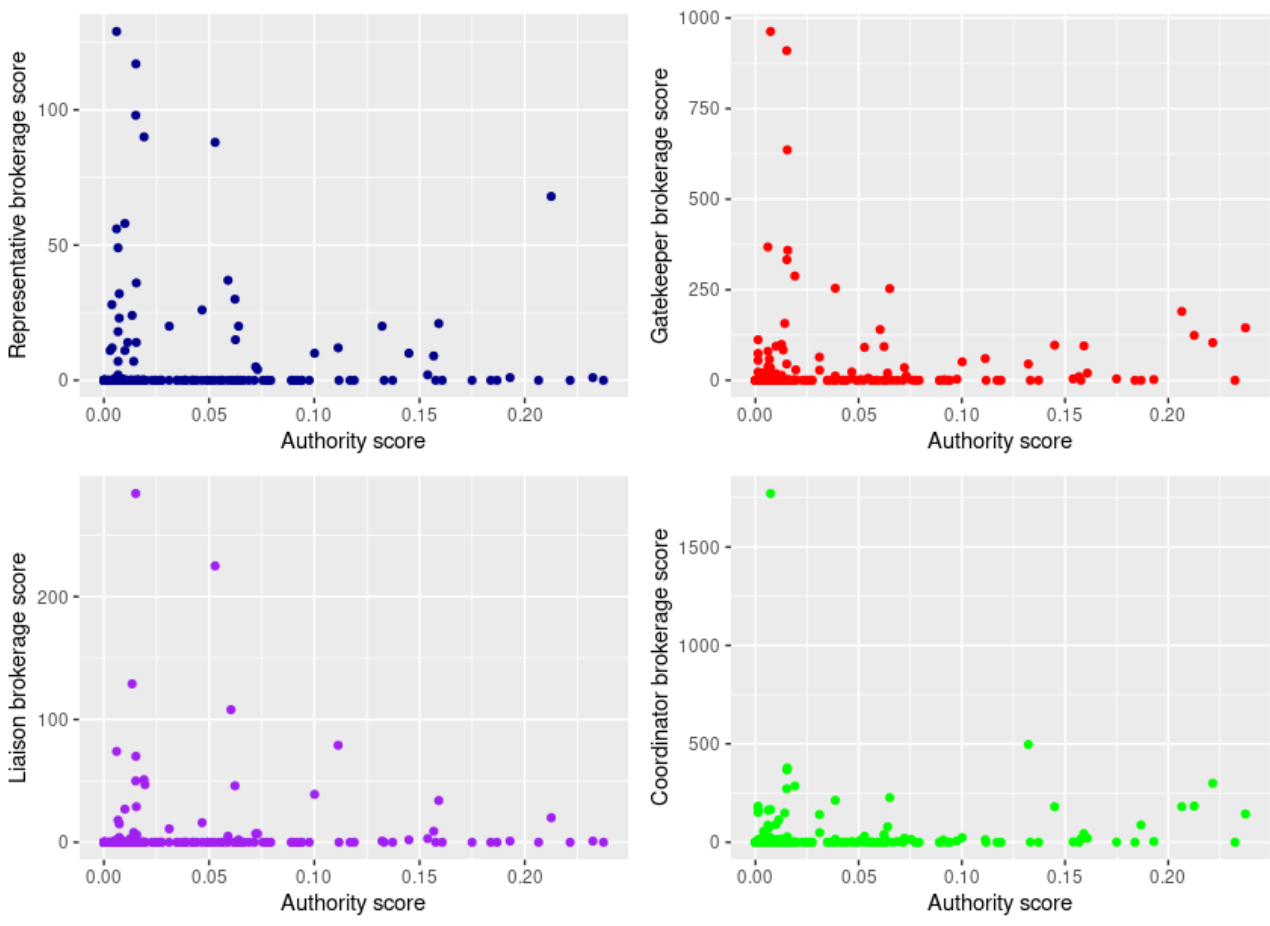

Figure 3. Association between authority scores and brokerage scores for the most politically-salient community in June 2019.

\section{Content analysis}

Moving to the content, top words of each topical cluster are displayed in Figure 4 with English translations of the top 10 words listed in Table 1 . We classified the clusters into six topics: Announcement, Recon, Discussion, News, Arrest News, Curses and also measured their prevalence across time and channel types. Announcement contains messages about upcoming protests and events. Recon reports information about the spotting of police officers and vehicles. The messages usually 
contain precise information of the location, time, and amount of police force (For example, "Tin Shui Wai 1706 Crossroad between XX and XX. 10 riot police has been deployed”). Discussion contains deliberations of protest tactics and also discussions about current affairs. Arrest News contains news on recent arrests, outcomes of trials, and court judgements. News contains links and extracts from news reports and articles as well as the discussion around them. The topic of Curses contains curses towards the "black cops", a term generally used to refer to the police officers who have committed police brutality and violated human rights during the suppression of protests. Common slur such as "death to the whole family of the black cops” (黑警死全家) and “Pokkai” (仆街), a common Cantonese insult phrase that can be translated as "bastards". The prevalence of topics is shown in Figure 5.

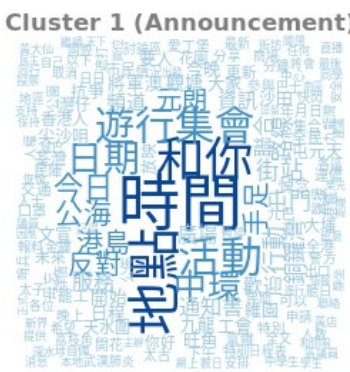

Cluster 5 (Recon)
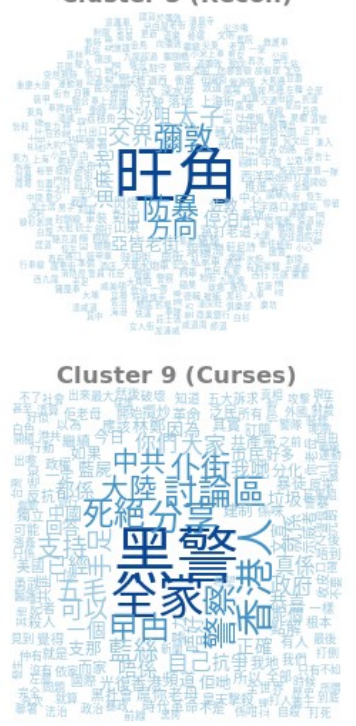
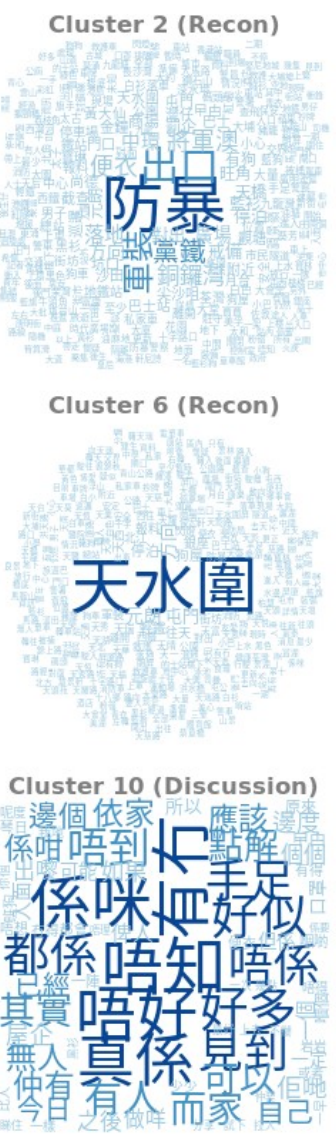
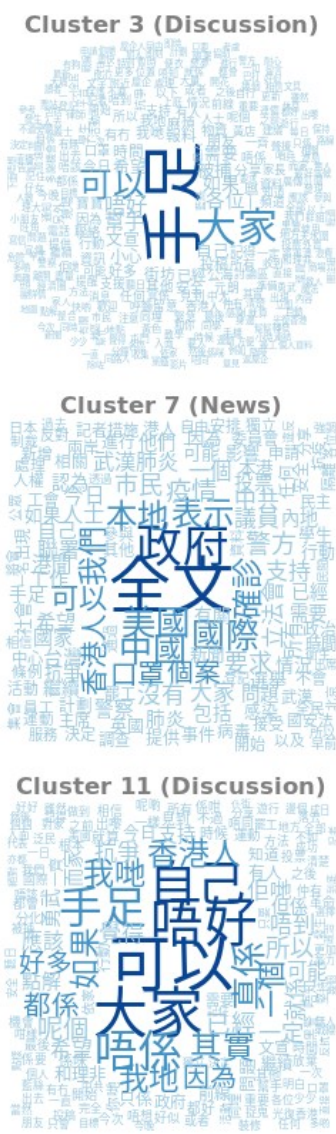
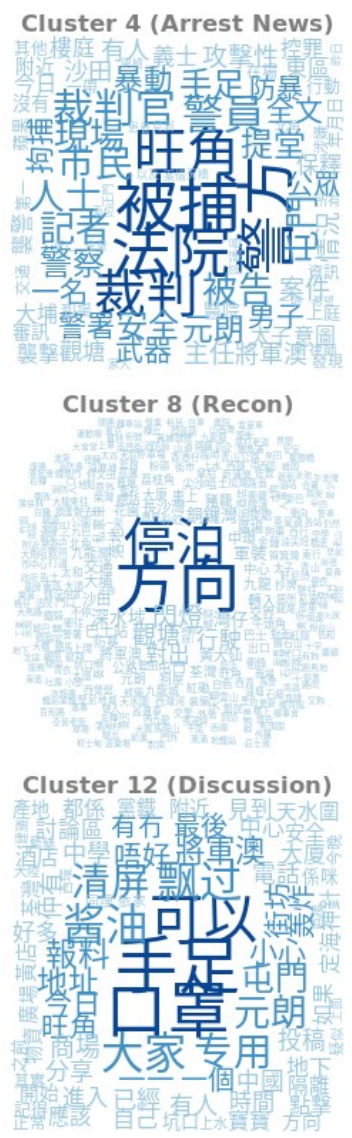

Figure 4. Wordclouds corresponding to 12 topic clusters.

Table 1. Topic Clusters

\begin{tabular}{|c|c|}
\hline Cluster & Translation of Top Words \\
\hline \multicolumn{2}{|c|}{ Announcement } \\
\hline 1 & Time, Location, With You, Activity, Assembly, Procession, Date, Central, Today, High Seas \\
\hline \multicolumn{2}{|l|}{ Recon } \\
\hline 2 & Riot, Exit, Military uniform, Party iron, Plainclothes, Tseung Kwan O, Causeway Bay, Landing, Central, Direction \\
\hline 5 & Mrong Kok, Sathên Road, Riot Police, Direction, Prince Edward, Junction, Yau Ma Tei, Tsim Sha Tsui, Parking, \\
\hline
\end{tabular}



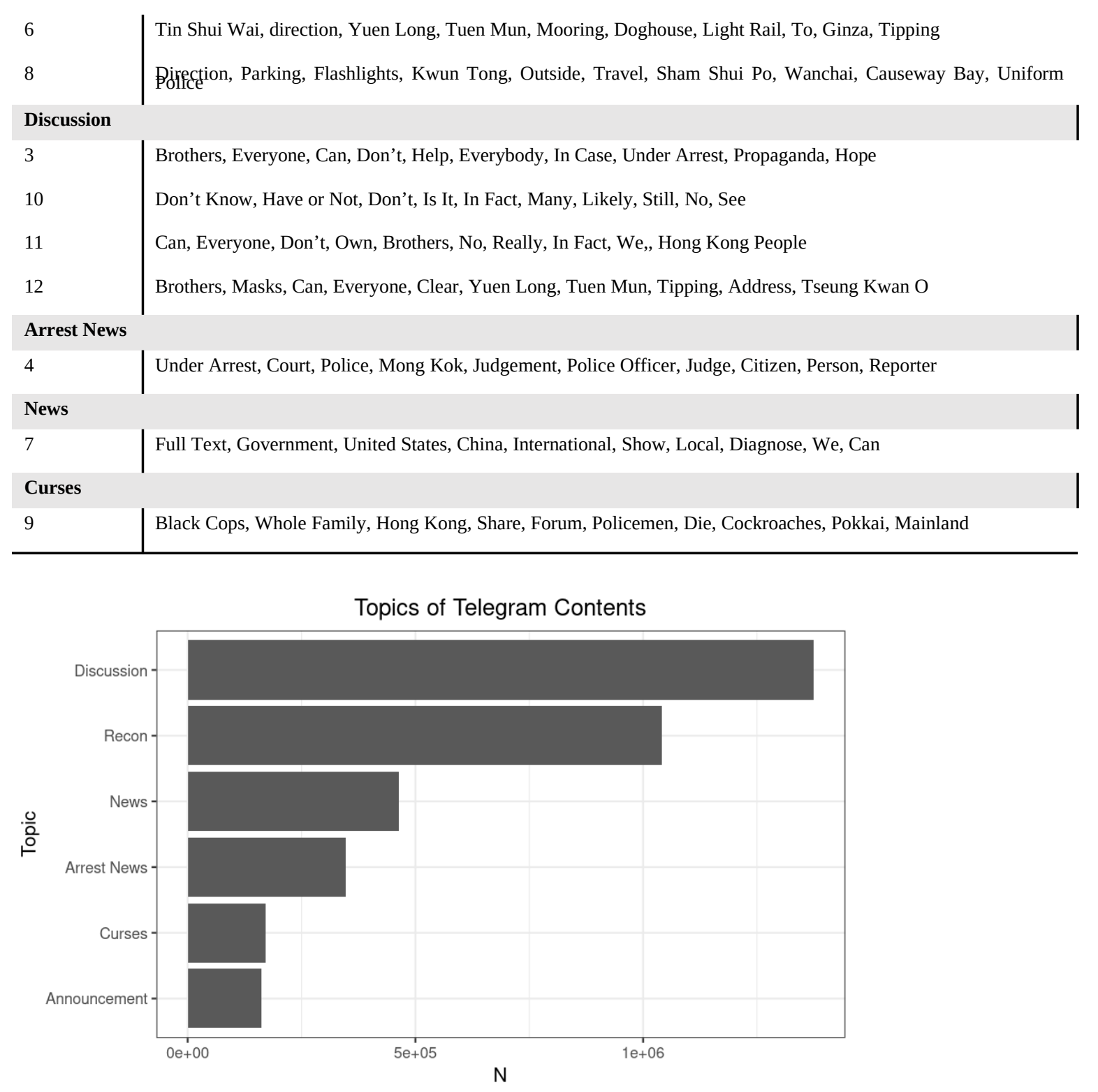

Figure 5. Prevalence of topics in analyzed Telegram content.

Figure 6 shows the relative prevalence of topics among channels of different roles. Channels performing different structural roles on the Telegram citation network tend to address different topics. More than $50 \%$ of the messages posted by high-authority channels belong to the Recon topic while it is only around $20 \%$ for the hub channels. Authority channels also post slightly more News and Arrest News than the hubs. On the other hand, more than $40 \%$ of messages of hub channels belong to the Discussion topic. There are significantly more Curses messages among the hubs than among authorities although the topic only accounts for less than $10 \%$ of all messages. The evidence suggests that Authority channels serve as the outlet for the flow of key information relevant to the protest while the Hub channels act as the platform for the deliberation among protesters. 


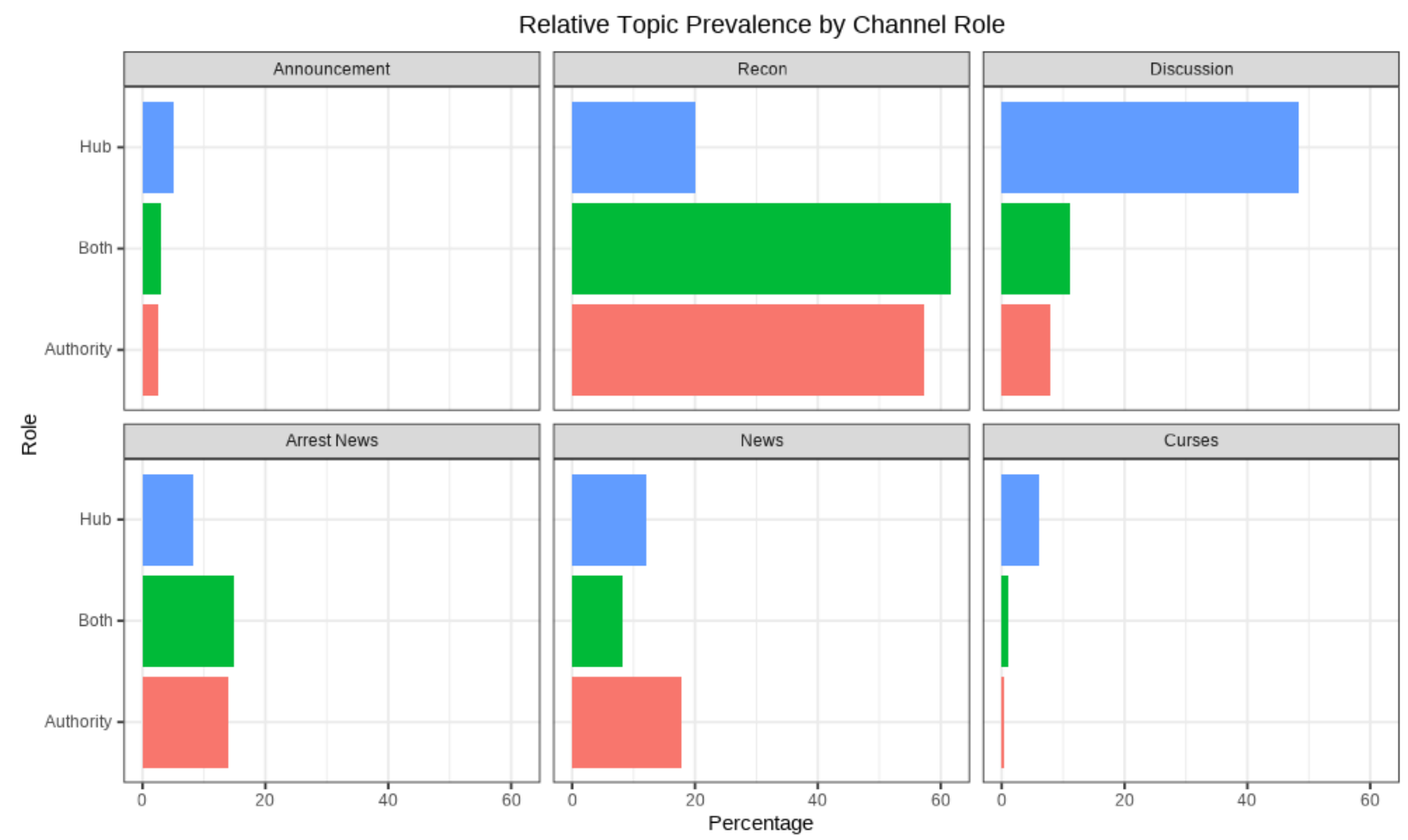

Figure 6. Relative Topic Prevalence by Channel Role.

Figure 7 shows the relative prevalence of different topics across time. The red dashed line denotes the date when the National Security Law was enacted. We can observe two peaks of the Recon topic: one in mid-November 2019 during the city-wide strike and another in mid-May 2020 during the "Sing With You” protests after the ease in coronavirus lockdown. For the topic of Discussion, we can observe several overlapping peaks in the second half of 2019, leading to the climax in mid-November. All of Announcement, Arrest News, and Curses follow a similar trend with a peak around late 2019. The topic of News peaked in late January during the outbreak of COVID-19. 
Topic Prevalence across Time
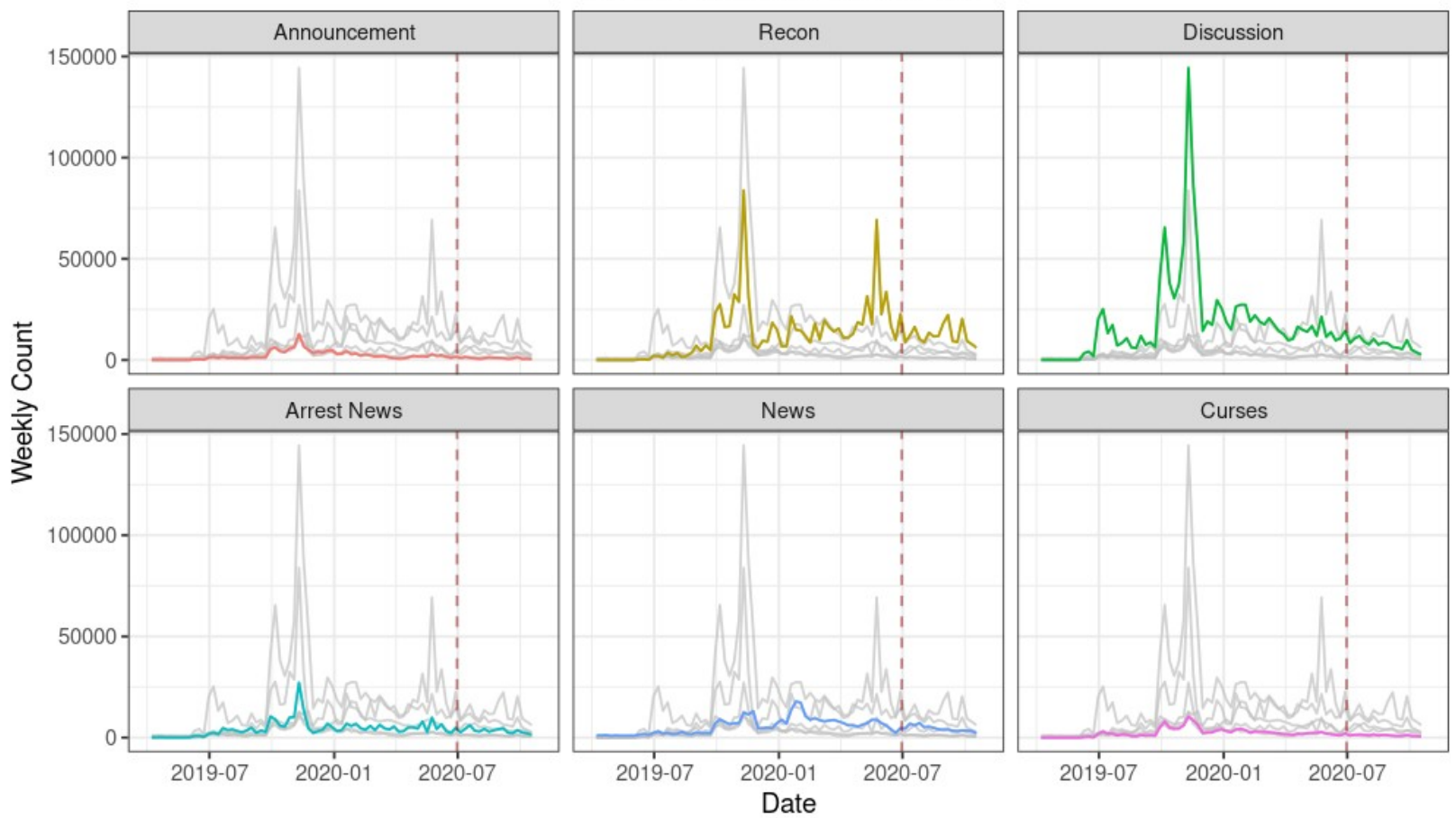

Figure 7. Topic Prevalence across Time. Red line corresponds to the introduction of the National Security Law.

\section{Leaderless or not?}

The changes in the positions of channels by authority score and hub score are presented in Figure 9, respectively. In these figures, we include only the data on top-50 positions for each month (i.e., if a channel dropped below top 50 in a given month, its data point for this month is omitted from the figures) to make the figures more illustrative of the dynamics around the top positions. Each line corresponds to one Telegram source. To make the figure easier to interpret for those not familiar with individual Telegram channels and groups as well as to protect the identities of the most influential sources in light of the National Security Law, we report source types instead of particular source names. The classification of the types was done manually by one of the authors who is fluent in Cantonese and Mandarin and is highly familiar with the local context due to the focus of their research.

As evident from Figure 8, there was a lot of volatility in the positions of top sources by authority and hub scores. We suggest that this indicates the absence of specific leaders of the protest, at least on Telegram. What is more, local community channels - i.e., those related to specific districts of Hong Kong, - were important as hubs and thus played a crucial role in disseminating protest-related information. Notably, in terms of both, hub and authority, Hong Kong-wide channels rather than media outlets, political parties or civic organizations (i.e. traditional leaders of past protests in Hong Kong including the Umbrella Movement) were predominantly important. However, the relative prominence of specific Hong Kongwide sources was changing, highlighting the absence of specific leader channels among them. 
(a) Changes in Positions by Authority Rank
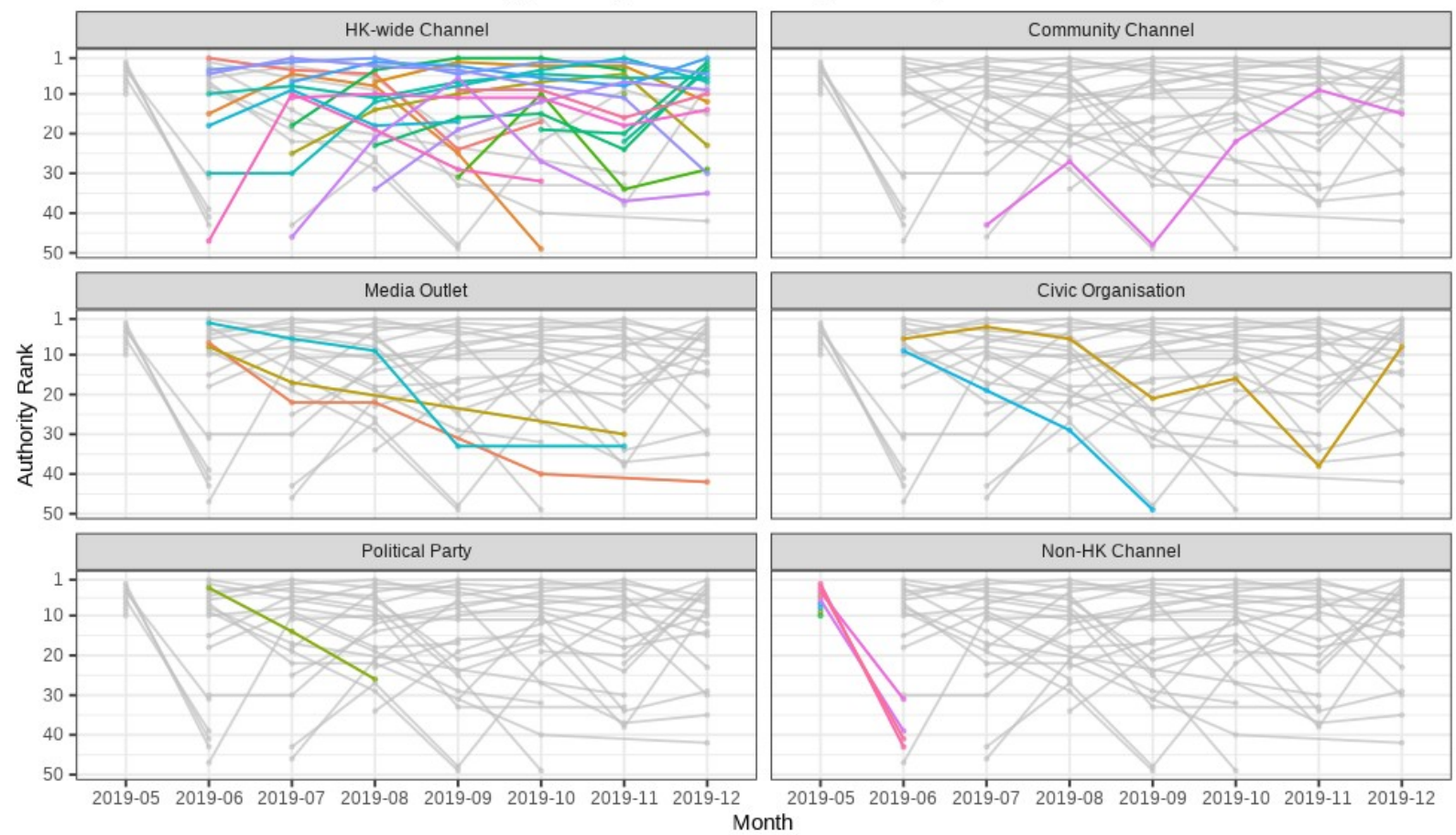

(b) Changes in Positions by Hub Rank
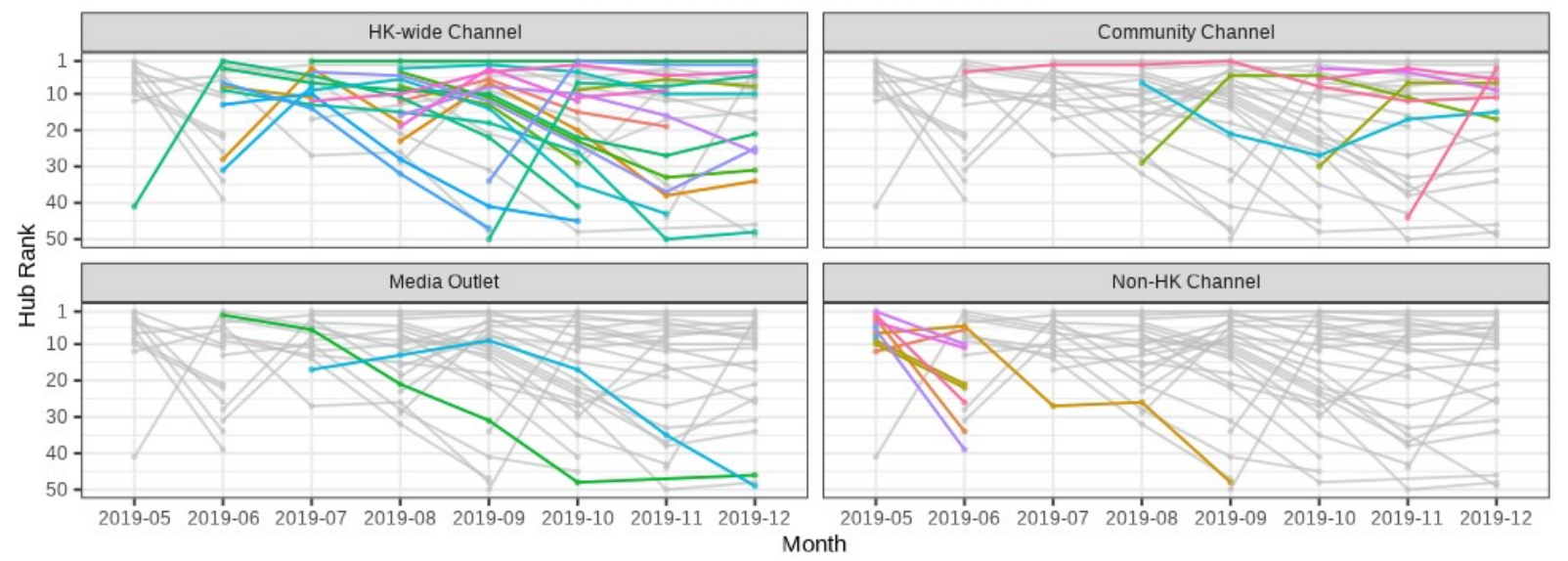

Figure 8. Changes in the channel/group positions by authority and hub score by month.

\section{Cooldown after National Security Law}

We find significant ( $\mathrm{p}<0.01$ : 95\% CI, 3.3106-26.551) variation in the levels of activity between the 4month period before the enactment of the National Security Law and the 3-month period after the introduction of the law. Before the introduction of the legislation, the mean daily rate of edge creation in the network was 14990.451(SD=8271.572), and after - 9229.065 (SD=2605.587). Corresponding ITS plot is 
reported in Figure 9. Hence, the introduction of the National Security law has a triggered a significant decrease in the activity of the observed Telegram network.

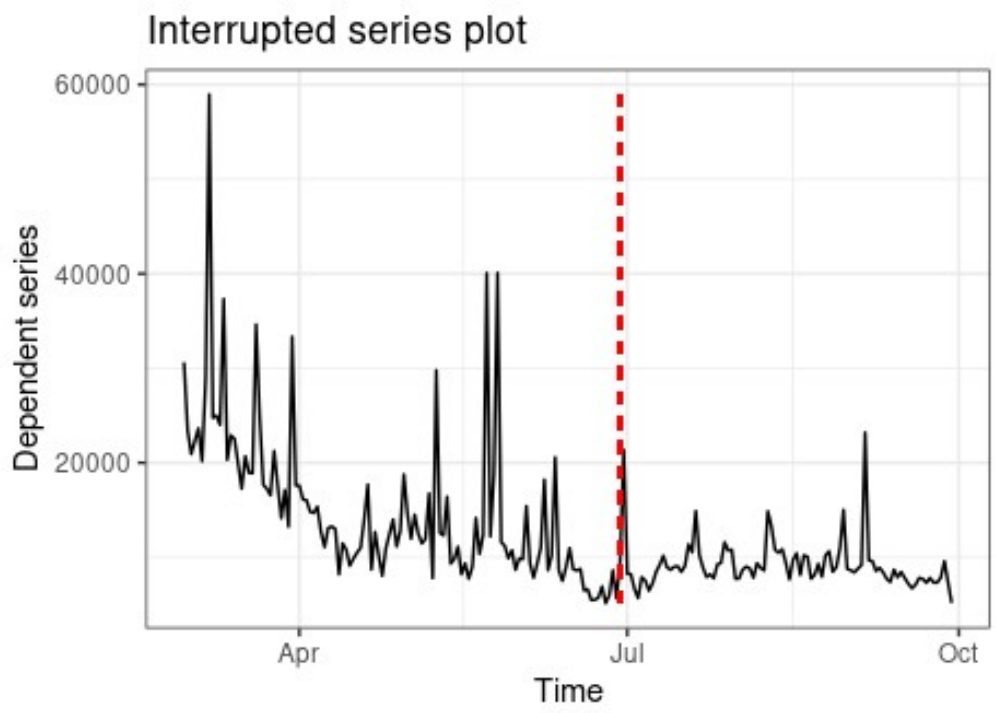

Figure 9. ITS plot of edge-creation activity on the Telegram network, red line marks the introduction of the National Security Law.

We have also analyzed the prevalence of different topics in Telegram content before and after the enactment of the Security Law (Figure 10). Most topics follow similar distribution before and after the enactment of the law, with the exception of Discussion and Recon. The evidence suggests that the Telegram users engaged relatively less in discussion about current issues and protest strategy and more in reconnaissance. However, it is important to note that the absolute amount of both Discussion and Recon after the Security Law was smaller than the amount before the Security Law. Further analysis when more data points become available would be needed to substantiate the observation. 


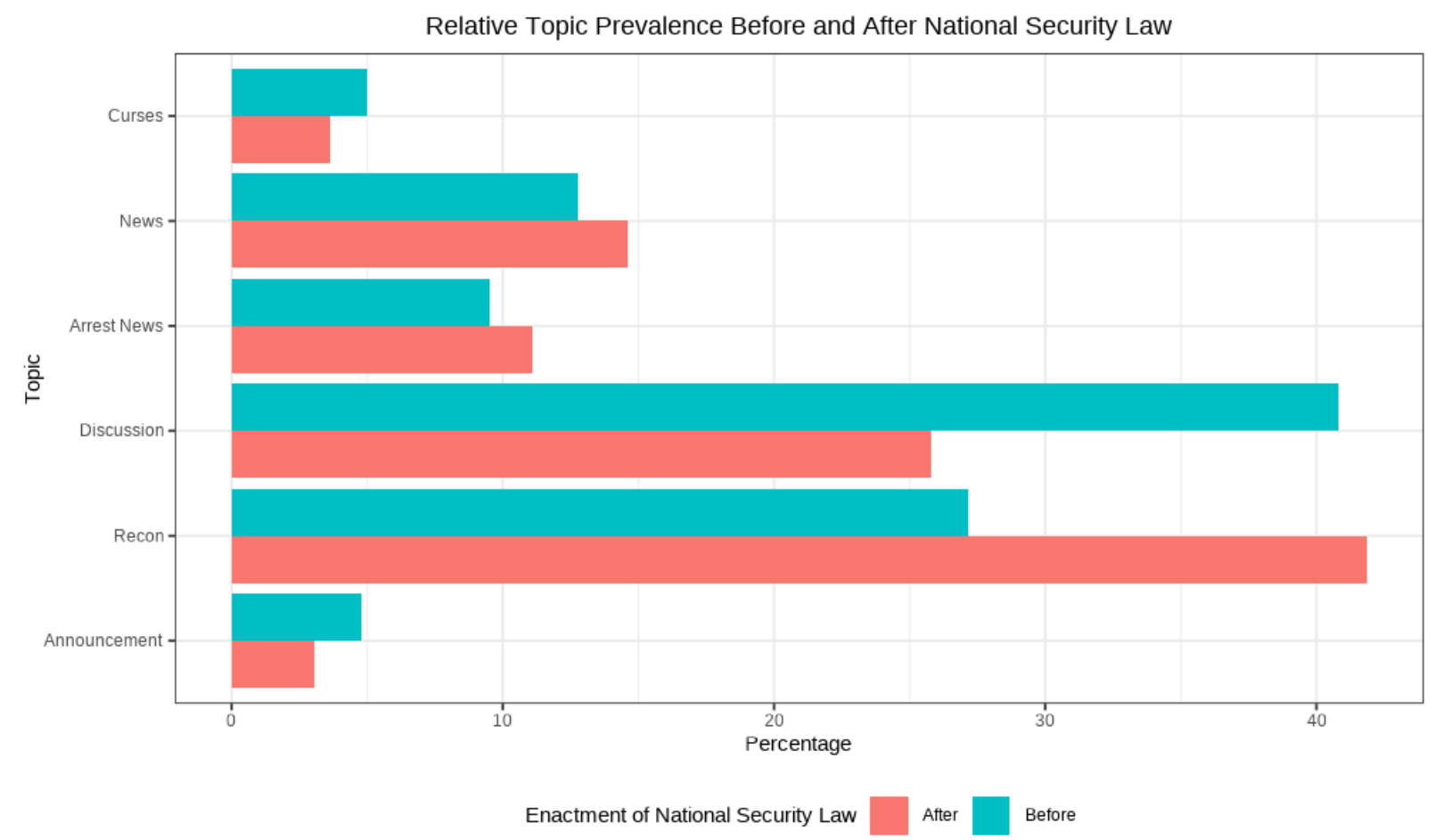

Figure 10. Topic Prevalence Before and After the National Security Law.

\section{Conclusion and discussion}

Our analysis has revealed that Telegram became popular with Hong Kong's political activists in June 2019, when major protests against the Extradition Bill occurred with protesters surrounding the LegCo and blocking the introduction of the legislation. Since then the Hong Kongese Telegramsphere was swiftly growing throughout 2019 with the growth peaking in the fall simultaneously with the most active protest actions.

Importantly, the citation network on Telegram, fragmented in the beginning, rapidly became cohesive, thus fostering the efficiency of the spread of information. The non-fragmented structure of citation networks is of particular relevance on Telegram given that it is difficult to search for specific channels and groups unless they are cited by others. In the case of Hong Kong protests, it ensured the efficient diffusion of information among local and city-wide communities. Channels and groups that connected the political community to other communities in the early stage of the network formation might have fostered the increased cohesion. Notably, such broker channels were not particularly influential in the Telegramsphere. Still, their role in reaching out to other communities might have been crucial for the subsequent efficient spread of information in the network, suggesting that in the case of Telegram-based protests such "low key" actors can be of high importance in this sense.

Text analysis results demonstrate that Telegram was used by the protesters mostly to distribute information related to police presence and protest-related events, as well as for deliberation. Channels and 
groups with high authority scores were dominated by information on protest-related events. In turn, those with high hub scores that aggregated such information from multiple high-authority sources, were used for discussion of further steps - possibly, based on the information about police presence and other events coming from high-authority sources. Thus, these two types of Telegram channels and groups worked in synergy. The type of information that was spread in Hong Kongese Telegramsphere is precisely the information that scholars find important for protest mobilization (Jost et al., 2018). Along with the fact that the observed network was cohesive making the spread of information efficient, this provides credible evidence that Telegram, as suggested by the media before (Schectman, 2019), played a crucial instrumental role in the organization of 2019 protests in Hong Kong.

The analysis also reveals that the protests were de-facto leaderless, as previously claimed (Ting, 2020), with different sources switching in terms of the dominance in the network every month. Remarkably, local community channels and groups were of significant importance for the coordination and distribution of information in the network. Anecdotal evidence suggests that local group chats and channels also play an important role in Telegram-based protest mobilization in Belarus - activists even compiled a map listing local community Telegram sources (Dze.Chat, n.d.). This is an indication that Telegram might be a platform that fosters synergetic development of connective and collective action, promoting community building on the local level and the connections between such local communities. Seemingly, these are such communities that play crucial role in protest coordination and deliberation, without specific leaders. Further analysis of Telegram-aided protests in different contexts is necessary to scrutinize these claims and establish whether our observations hold true in the contexts other than Hong Kong.

Finally, interrupted time series analysis results show that the National Security Law introduced in July 2020 has triggered a significant decrease in Telegram-based activity. This is a troubling observation since it suggests that even an app that is somewhat immune to online censorship such as Telegram is of little help against a powerful autocratic state such as China, shall it resolve to harsh offline measures to curb protest mobilization. However, we have analyzed only a period of three months since the introduction of the Law. We believe that right now it is impossible to say how effective the Security Law is for curbing protest mobilization in Hong Kong in long term perspective. A follow-up analysis of the developments will be necessary to assess this once more time passes since the introduction of the Law. Hong Kong has experienced harsh crackdowns before, for instance, after the Umbrella Movement of 2014, and nonetheless the protest movement in the city continued to evolve. It is possible that, following an initial cooldown and chilling effect, protest activities in Hong Kong - on Telegram or otherwise - will bounce back to pre-Security Law levels. As Joshua Wong and Jason Ng put it in the concluding remarks of their book "Unfree Speech": "In our case, the night is still young and our journey will get darker and and more perilous before it gets better” (Wong \& Ng, 2020). Such remarks from some of the most prominent Hong Kong's pro-democracy activists suggest that the Hong Kongese protesters have been anticipating further crackdowns on the movement but have no intention of giving up. 


\section{References}

Agence France-Presse. (2020, July 14). Hong Kong activist Nathan Law moves to Britain and vows fight will continue. Guardian. http://www.theguardian.com/world/2020/jul/14/hong-kong$\underline{\text { activist-nathan-law-moves-to-britain-and-vows-fight-will-continue }}$

Baltar, F., \& Brunet, I. (2012). Social research 2.0: Virtual snowball sampling method using Facebook. Internet Research, 22(1), 57-74. https://doi.org/10.1108/10662241211199960

Banjo, S. (2019, August 15). Hong Kong Protests Drive Surge in Telegram Chat App. Bloomberg.Com. https://www.bloomberg.com/news/articles/2019-08-15/hong-kong-protestsdrive-surge-in-popular-telegram-chat-app

Barron, L. (2020, July 23). “It’s So Much Worse Than Anyone Expected.” Why Hong Kong’s National Security Law Is Having Such a Chilling Effect. Time. https://time.com/5867000/hongkong-china-national-security-law-effect/

Bennett, W. L., \& Segerberg, A. (2012). The Logic of Connective Action. Information, Communication \& Society, 15(5), 739-768. https://doi.org/10.1080/1369118X.2012.670661

Biernacki, P., \& Waldorf, D. (1981). Snowball Sampling: Problems and Techniques of Chain Referral Sampling. Sociological Methods \& Research, 10(2), 141-163. https://doi.org/10.1177/004912418101000205

Blondel, V. D., Guillaume, J.-L., Lambiotte, R., \& Lefebvre, E. (2008). Fast unfolding of communities in large networks. Journal of Statistical Mechanics: Theory and Experiment, 2008(10), P10008. https://doi.org/10.1088/1742-5468/2008/10/P10008

Castells, M. (2015). Networks of Outrage and Hope: Social Movements in the Internet Age. John Wiley \& Sons.

Chinese Cyberattack Hits Telegram, App Used by Hong Kong Protesters-The New York Times. (n.d.). Retrieved October 30, 2020, from https://www.nytimes.com/2019/06/13/world/asia/hong-kong-telegram-protests.html 
Clarke, L. (2019, October 19). Catalonia has created a new kind of online activism. Everyone should pay attention. Wired UK. https://www.wired.co.uk/article/barcelonia-riots-catalonia-protests$\underline{\text { news }}$

Comunello, F., \& Anzera, G. (2012). Will the revolution be tweeted? A conceptual framework for understanding the social media and the Arab Spring. Islam and Christian-Muslim Relations, 23(4), 453-470. https://doi.org/10.1080/09596410.2012.712435

Comunello, F., Mulargia, S., \& Parisi, L. (2016). The 'Proper’ Way to Spread Ideas through Social Media: Exploring the Affordances and Constraints of Different Social Media Platforms as Perceived by Italian Activists. The Sociological Review, 64(3), 515-532. https://doi.org/10.1111/1467-954X.12378

Dans, E. (2020). Belarus, Telegram And Pavel Durov’s Revenge. Forbes. https://www.forbes.com/sites/enriquedans/2020/09/05/belarus-telegram-and-pavel-durovsrevenge/

Dze.chat. (n.d.). Retrieved November 3, 2020, from http://dze.chat/

Ebel, F. (2019, September 6). Outlawed app emerges as key tool for Russian protesters. AP NEWS. https://apnews.com/article/34df8b282f6c4fd188a33d2fb3ff381c

Egn2020244872.pdf. (n.d.). Retrieved October 30, 2020, from https://www.gld.gov.hk/egazette/pdf/20202448e/egn2020244872.pdf

English, P. (2019). its.analysis: Running Interrupted Time Series Analysis (1.4.1) [Computer software]. https://CRAN.R-project.org/package=its.analysis

Etikan, I. (2016). Comparision of Snowball Sampling and Sequential Sampling Technique. Biometrics \& Biostatistics International Journal, 3(1). https://doi.org/10.15406/bbij.2016.03.00055

Exo, L. (2020). Telethon: Full-featured Telegram client library for Python 3 (1.11.2) [Python]. https://github.com/LonamiWebs/Telethon

Gerbaudo, P. (2012). Tweets and the Streets: Social Media and Contemporary Activism. Pluto Press. 
https://library.oapen.org/handle/20.500.12657/30772

González-Bailón, S., \& Wang, N. (2016). Networked discontent: The anatomy of protest campaigns in social media. Social Networks, 44, 95-104. https://doi.org/10.1016/j.socnet.2015.07.003

Goodman, L. A. (1961). Snowball Sampling. Annals of Mathematical Statistics, 32(1), 148-170. https://doi.org/10.1214/aoms/1177705148

Gould, R. V., \& Fernandez, R. M. (1989). Structures of Mediation: A Formal Approach to Brokerage in Transaction Networks. Sociological Methodology, 19, 89-126. https://doi.org/10.2307/270949

Ho, J. C. (2020). Songotsti. A Package for Cantonese Tokenisation. https://github.com/justinchuntingho/songotsti

Hong Kong Government. (2020). The Law of the People's Republic of China on Safeguarding National Security in the Hong Kong Special Administrative Region. https://www.gld.gov.hk/egazette/pdf/20202448e/egn2020244872.pdf

Howard, P. N., Duffy, A., Freelon, D., Hussain, M. M., Mari, W., \& Maziad, M. (2011). Opening Closed Regimes: What Was the Role of Social Media During the Arab Spring? (SSRN Scholarly Paper ID 2595096). Social Science Research Network. https://papers.ssrn.com/abstract=2595096

Jost, J. T., Barberá, P., Bonneau, R., Langer, M., Metzger, M., Nagler, J., Sterling, J., \& Tucker, J. A. (2018). How Social Media Facilitates Political Protest: Information, Motivation, and Social Networks. Political Psychology, 39(S1), 85-118. https://doi.org/10.1111/pops.12478

Kent, E. (2019, September 2). No poster boys, no organisers: Hong Kong’s leaderless resistance faces a leaderless government. Hong Kong Free Press. https://hongkongfp.com/2019/09/02/noposter-boys-no-organisers-hong-kongs-leaderless-resistance-faces-leaderless-government/

Kleinberg, J. M. (1998). Authoritative sources in a hyperlinked environment. Proceedings of the Ninth Annual ACM-SIAM Symposium on Discrete Algorithms, 668-677.

Ku, A. S. (2020). New forms of youth activism - Hong Kong's Anti-Extradition Bill movement in 
the local-national-global nexus. Space and Polity, 24(1), 111-117.

https://doi.org/10.1080/13562576.2020.1732201

Lee, F. (2020). Solidarity in the Anti-Extradition Bill movement in Hong Kong. Critical Asian Studies, 52(1), 18-32. https://doi.org/10.1080/14672715.2020.1700629

Lee, F. L. F., Yuen, S., Tang, G., \& Cheng, E. W. (2019). Hong Kong’s Summer of Uprising: From Anti-Extradition to Anti-Authoritarian Protests. China Review, 19(4), 1-32.

Lee, P. S. N., So, C. Y. K., \& Leung, L. (2015). Social media and Umbrella Movement: Insurgent public sphere in formation. Chinese Journal of Communication, 8(4), 356-375. https://doi.org/10.1080/17544750.2015.1088874

Leigh, K., Lung, N., \& Marlow, I. (2020, July 11). Here’s how China’s security law is already changing the face of Hong Kong. The Japan Times. https://www.japantimes.co.jp/news/2020/07/11/asia-pacific/crime-legal-asia-pacific/chinasecurity-law-hong-kong/

Liao, R., \& Lomas, N. (2020). Telegram pledges to make anti-censorship tools for Iran and China. TechCrunch. https://social.techcrunch.com/2020/06/22/telegram-anti-censorship-china-iran/

Liu, N., \& Yang, Y. (2020, June 30). Hong Kong pro-democracy groups disband after security law passed. https://www.ft.com/content/28aa95f9-e3b1-4b00-b25f-8de3d349f660

Lyebyedyev, Y., \& Makhortykh, M. (2018). \#Euromaidan: Quantitative Analysis of Multilingual Framing 2013-2014 Ukrainian Protests on Twitter. 2018 IEEE Second International Conference on Data Stream Mining Processing (DSMP), 276-280.

https://doi.org/10.1109/DSMP.2018.8478462

Maréchal, N. (2017). Networked Authoritarianism and the Geopolitics of Information: Understanding Russian Internet Policy. Media and Communication, 5(1), 29. https://doi.org/10.17645/mac.v5i1.808

McDowall, D., McCleary, R., \& Bartos, B. J. (2019). Interrupted Time Series Analysis. Oxford University Press. 
Mikolov, T., Chen, K., Corrado, G., \& Dean, J. (2013). Efficient Estimation of Word Representations in Vector Space. ArXiv:1301.3781 [Cs]. http://arxiv.org/abs/1301.3781

Morales, A. J., Losada, J. C., \& Benito, R. M. (2012). Users structure and behavior on an online social network during a political protest. Physica A: Statistical Mechanics and Its Applications, 391(21), 5244-5253. https://doi.org/10.1016/j.physa.2012.05.015

Mozur, P., \& Stevenson, A. (2019, June 13). Chinese Cyberattack Hits Telegram, App Used by Hong Kong Protesters-The New York Times. New York Times. https://www.nytimes.com/2019/06/13/world/asia/hong-kong-telegram-protests.html

Newman, M. E. J., \& Girvan, M. (2004). Finding and evaluating community structure in networks. Physical Review E, 69(2), 026113. https://doi.org/10.1103/PhysRevE.69.026113

Partz, H. (2020). Telegram supports protests in Belarus with new opposition flag emoji. Cointelegraph. https://cointelegraph.com/news/telegram-supports-protests-in-belarus-with-newopposition-flag-emoji

Poell, T., Abdulla, R., Rieder, B., Woltering, R., \& Zack, L. (2016). Protest leadership in the age of social media. Information, Communication \& Society, 19(7), 994-1014. https://doi.org/10.1080/1369118X.2015.1088049

Rachman, G., Mander, B., Dombey, D., Wong, S.-L., \& Saleh, H. (2019, May 10). Leaderless rebellion: How social media enables global protests. Financial Times. https://www.ft.com/content/19dc5dfe-f67b-11e9-a79c-bc9acae3b654

Ruijgrok, K. (2017). From the web to the streets: Internet and protests under authoritarian regimes. Democratization, 24(3), 498-520. https://doi.org/10.1080/13510347.2016.1223630

Schectman, J. (2019, August 31). Exclusive: Messaging app Telegram moves to protect identity of Hong Kong protesters. Reuters. https://www.reuters.com/article/us-hongkong-telegramexclusive-idUSKCN1VK2NI

Sculley, D. (2010). Web-scale k-means clustering. Proceedings of the 19th International Conference on World Wide Web - WWW '10, 1177. https://doi.org/10.1145/1772690.1772862 
Siu, J., \& Leung, C. (2020, August 28). Alleged Hong Kong Telegram channel administrator charged with inciting arson. South China Morning Post. https://www.scmp.com/news/hongkong/law-and-crime/article/3099336/hong-kong-protests-alleged-telegram-channel

Snapshot. (n.d.). Retrieved October 28, 2020, from https://www.bloomberg.com/news/articles/201908-15/hong-kong-protests-drive-surge-in-popular-telegram-chat-app

Spaiser, V., Chadefaux, T., Donnay, K., Russmann, F., \& Helbing, D. (2017). Communication power struggles on social media: A case study of the 2011-12 Russian protests. Journal of Information Technology \& Politics, 14(2), 132-153. https://doi.org/10.1080/19331681.2017.1308288

Sun, J. (n.d.). Jieba Chinese Word Segmentation (结巴中文分词). https://github.com/fxsjy/jieba Telegram F.A.Q. (n.d.). Telegram. Retrieved November 1, 2019, from https://telegram.org/faq Ting, T. (2020). From 'be water' to 'be fire’: Nascent smart mob and networked protests in Hong Kong. Social Movement Studies, 19(3), 362-368. https://doi.org/10.1080/14742837.2020.1727736

Tufekci, Z. (2017). Twitter and Tear Gas: The Power and Fragility of Networked Protest. Yale University Press.

Tufekci, Z., \& Wilson, C. (2012). Social Media and the Decision to Participate in Political Protest: Observations From Tahrir Square. Journal of Communication, 62(2), 363-379. https://doi.org/10.1111/j.1460-2466.2012.01629.x

Urman, A., \& Katz, S. (2020). What they do in the shadows: Examining the far-right networks on Telegram. Information, Communication \& Society, O(0), 1-20. https://doi.org/10.1080/1369118X.2020.1803946

Vincent, D. (2019, June 29). How apps power Hong Kong’s “leaderless” protests. BBC News. https://www.bbc.com/news/technology-48802125

Wong, B. (2020, March 30). Hong Kong Telegram group operator accused of inciting violence against police. South China Morning Post. https://www.scmp.com/news/hong-kong/law-and- 
crime/article/3077607/hong-kong-protests-telegram-group-operator-faces

Wong, J., \& Ng, J. Y. (2020). Unfree Speech: The Threat to Global Democracy and Why We Must Act, Now. Random House. 